\title{
Forty years of MTS studies in the Ukraine
}

\author{
Alexander I. Ingerov ${ }^{1}$, Igor I. Rokityansky², and Viktor I. Tregubenko ${ }^{3}$ \\ ${ }^{1}$ Dneprogeophysica, Geological Survey of Ukraine, Ukraine \\ ${ }^{2}$ Institute of Geophysics, POB-338/7, Kiev-146, Ukraine \\ ${ }^{3}$ Geological Prospecting Institute, 78 Avtozavodskaya str., Kiev-254114, Ukraine
}

(Received December 11, 1998; Revised May 25, 1999; Accepted July 12, 1999)

\begin{abstract}
Extensive EM studies have been made in the Ukraine during the last 40 years and a set of reliable results have been received. Data from 3000 Magnetotelluric soundings are presented as maps of effective apparent resistivity at periods of $150 \mathrm{~s}$ and $500 \mathrm{~s}$ and impedance phase at $T=150 \mathrm{~s}$. The principal results are: $\mathrm{S} 1 \mathrm{map}$ at the scale 1:2500000, tracing and study of Carpathian, Kirovograd and Donbas regional conductivity anomalies, a map of the crustal conductivity for Ukrainian Shield, a study of faults.
\end{abstract}

\section{Introduction}

In 1958 Dr. Nina V. Lipskaya added two horizontal magnetic components to the electric field ( $\langle\langle$ Earth currents $\rangle)$ measurements performed since 1957 within the framework of the International Geophysical Year in the observatories Koretz in the Ukrainian Shield and Alushta in Crimea. An analysis of the observed electromagnetic (EM) field behavior in Alushta provided new results: the detection of magnetotelluric (MT) field anisotropy (Rokityansky, 1961) and coastal effect regularities (Rokityansky, 1963). The deep magnetotelluric curve in Koretz constructed by Lipskaya (Tikhonov et al., 1964) is one of the first bearing information about the mantle conducting layer - the electrical astenosphere. By analysing deep MTS curves Rokityansky introduced the idea of static (galvanic) distortions, and proposed the correcting shift of statically distorted MTS curves by tying them to global GDS data (Rokityansky, 1970, 1971, 1982). In the 1960's and 1970's MTS were conducted in sedimentary basins for oil prospecting. A dozen deep MTS were made by analog MTstations of the Institute of Geophysics but reliability of the results was uncertain. Meanwhile, the MVP (GDS) method was improved, three hundreds field observations were made, and regional conductivity anomalies were traced and studied (Bondarenko et al., 1972; Rokityansky, 1982).

Since the Vranchea 1977 earthquake (felt in Kiev and Moscow) areat MTS Project has been in operation by Geophysical Expeditions in Dnepropetrovsk (Ingerov) and Kiev (Tregubenko) during the 1980's with a slow dying away in the 1990's. From 5 to 10 digital field laboratories made observations during six months in each of 15 years. More than 3000 deep MT soundings in the period interval of 0.1-3000 s and 8000 MTS in the interval 0.1-100 s have been recorded, processed, analysed and presented as curves of apparent resistivity, impedance phase and magnetic transfer function along measurement lines and effective ones as well as polar

Copy right (C) The Society of Geomagnetism and Earth, Planetary and Space Sciences (SGEPSS); The Seismological Society of Japan; The Volcanological Society of Japan; The Geodetic Society of Japan; The Japanese Society for Planetary Sciences. diagrams for selected periods. Pseudo-cross-sections along 4 geotraverses and a dozen shorter profiles were constructed. 2D models for selected structurs and thin sheet models were calculated. Preliminary interpretation has been completed but only a small part of the results, dealing with some parts of the territory, has been published (Rokityansky and Ingerov, 1986; Rokityansky et al., 1988, 1989, 1994). This work is the first attempt to present the MT data and preliminary geological results for the whole Ukraine.

\section{Geological Setting}

The central tectonic unit of the territory is the Ukrainian Shield. It is subdivided into major geological units-geoblocks: Volyn-Podolian (VP), Kirovograd (KG), NearDnieper (ND) and Near-Azov (NA) (Fig. 1). The oldest fold systems aged at $2.6 \mathrm{Ga}$ are known in the Near-Dnieper block. Archean-early Proterozoic folding (2.6-2.1 Ga) is observed in the south-west part of VP block in the Dniester-Bug region. Proterozoic folding with an age of $2.1-1.75 \mathrm{Ga}$ is seen in the rest at the territory. The crystalline Precambrian basement in the Ukrainian Shield is covered by Neogene-Quaternary sediments with thicknesses varying from zero to a few hundreds of meters. Outside the Shield the crystalline basement gently sinks (deepens) and further meets the slopes of the Shield and adjacent Paleozoic depressions: Pripyat Trough in the North, Dnieper-Donetsk Paleorift and Donbas folding system (D) in the North-North-East, Indolo-Kuban basin and Near-Black-See depression in the South, Volyn-Podolian Plate and Pre-Carpathian depression in the West. The folded Alpine systems of the Crimea (Cr) and Carpathians (C) are situated at Southern and Western borders of the Ukraine. Active geodynamic processes and earthquakes occur in the latter two regions.

\section{MTS Data Description}

The location of wide-band 0.1-3000 s MTS observations is given by dots in Fig. 2. Thousands of MTS curves have been constructed and analyzed. We placed them in $50 \times 50$ 


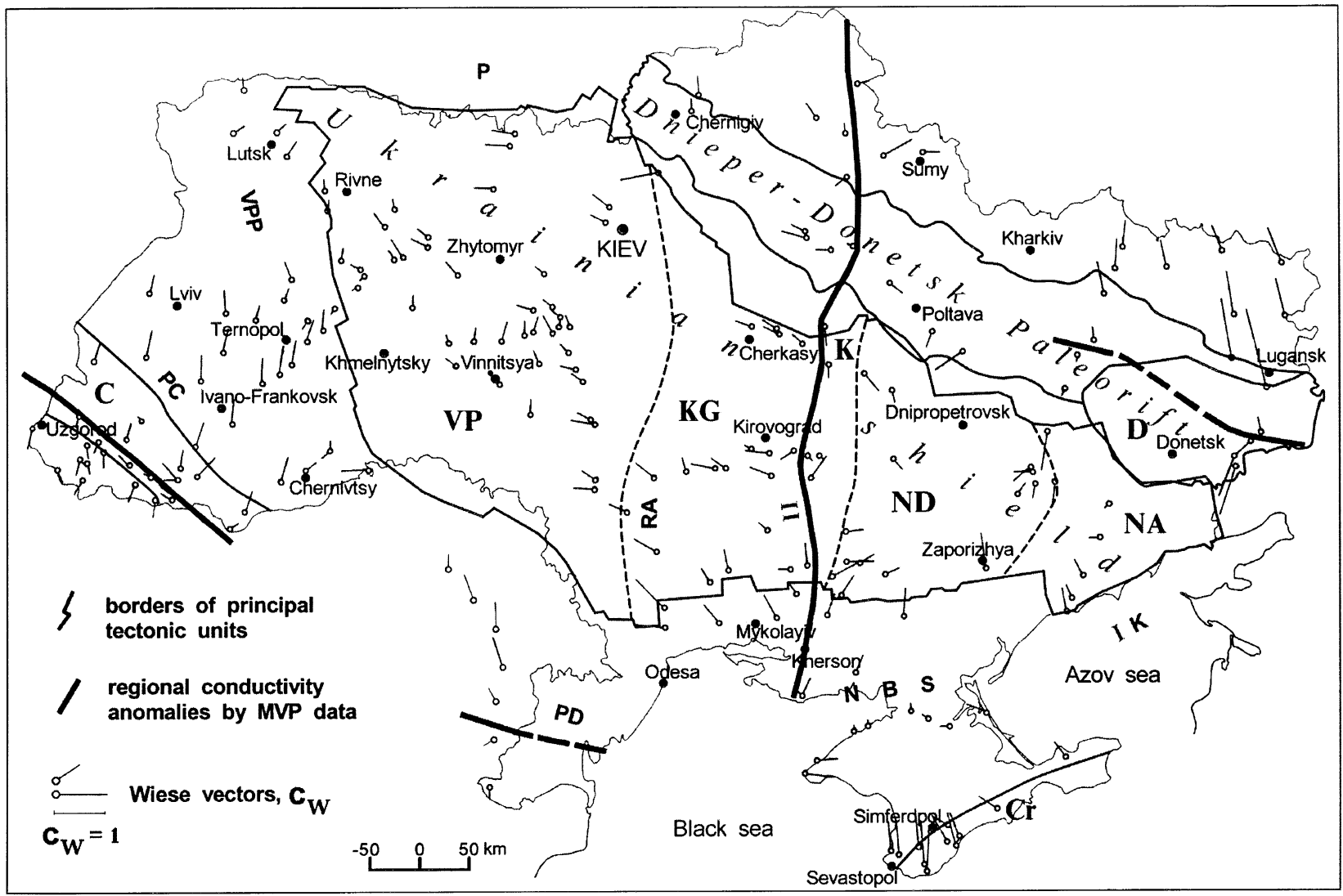

Fig. 1. Principal geological units, Wiese vectors for period $1800 \mathrm{~s}$ and regional conductivity anomalies: C - Carpathian, K - Kirovograd, D - Donbas. Geoblocks of the Ukrainian Shield: VP - Volhino-Podolsk, KG - Kirovograd, ND - Near-Dnieper, NA - Near-Azov. Cr - Crimea folded Apline system. VPP - Volyn Podolian Plate. Paleozoic depressions: P - Pripyat, IK - Indolo-Kuban, NBS - Near Black Sea, PD - Pre-Dobrudgian, PC - Pre-Carpatian. Proterozoic structures of Kirovograd geoblock: RA - Ryasnopol, II - Indolo-Inguletz.

$\mathrm{km}$ and $25 \times 25 \mathrm{~km}$ cells to define a representative mean curve in every cell. Averaging makes a sense when all the averaged MTS curves are of the same form (conformal curves); that is the case both for non-distorted curves and those distorted by a static shift. On the slopes of the shield and in the sedimentary basins MTS curves meet the requirement of conformity in half of the $50 \times 50 \mathrm{~km}$ cells and in $80 \%$ of the $25 \times 25 \mathrm{~km}$ cells. Examples of almost coincident conformal curves can be seen in Fig. 3 for the Pre-Dobrudga depression (PD). In the rest of the cells the variability of the curves' shape makes averaging senseless. The latter is the case for majority of the cells within the Shield. It means that in the conditions of the Ukrainian Shield the local distortions frequently have a nonstatic character: they are frequency-dependent up to rather long periods (Fig. 3, curve DF), which is inconsistent with a small spatial extent for the anomalies under a relatively resistive shield environment. In most cases, such anomalies are observed over faults and suture zones, and especially in zones, where they cross, some of which were surveyed by detailed short-period-band MTS. 2D-modelling of vertical and inclined faults with different conductivity distribution froms the basis for an explanation of some anomalies, others need 3D modelling.In conclusion we can say that MTS survey is an effective tool for the discovery of unknown faults and the detailed study of known faults of different scale and also fault intersections. The objects mentioned are usually perspective for different mineral deposits. MTS surveys in the Ukrainian Shield show that the deep conductive faults have a tendency to form regular systems with preferred azimuths of fault directions $(0,17,45,90$ and 110 degrees $)$ and a regular spacing between faults of approximately $35 \mathrm{~km}$. Selected MTS curves are given in Fig. 3. They do not represent all the variety of data but only illuminate a few structures that will be discussed below. Some of the curves are published (Rokityansky et al., 1989, 1994-Donbas anomaly, Rokityansky and Ingerov, 1986 and elsewhere). Most of them are only discribed in official reports of the expeditions involved. Two examples when families of MTS curves in the Shield can be roughly treated as conformal are presented in Fig. 3 for the Ryasnopol (RA) and Kirovograd (K) crustal conductivity anomalies.

\section{Investigations of Regional Electrical Conductiv- ity Anomalies by MVP-MTS Data}

Field observations of geomagnetic variations were begun in the late 1960's to investigate the deep upper mantle structure using Geomagnetic Deep Sounding (GDS) technique. The analysis the spatial behaviour of geomagnetic variations gives evidence that the problem of the local GDS is not so simple as we conceived (Rokityansky, 1982). On the other hand, local anomalies of geomagnetic variations manifesting crustal conductivity anomalies were found. Three regional conductivity anomalies are known in the Ukraine: Carpathian (Bondarenko et al., 1972; Rokityansky, 1972, 


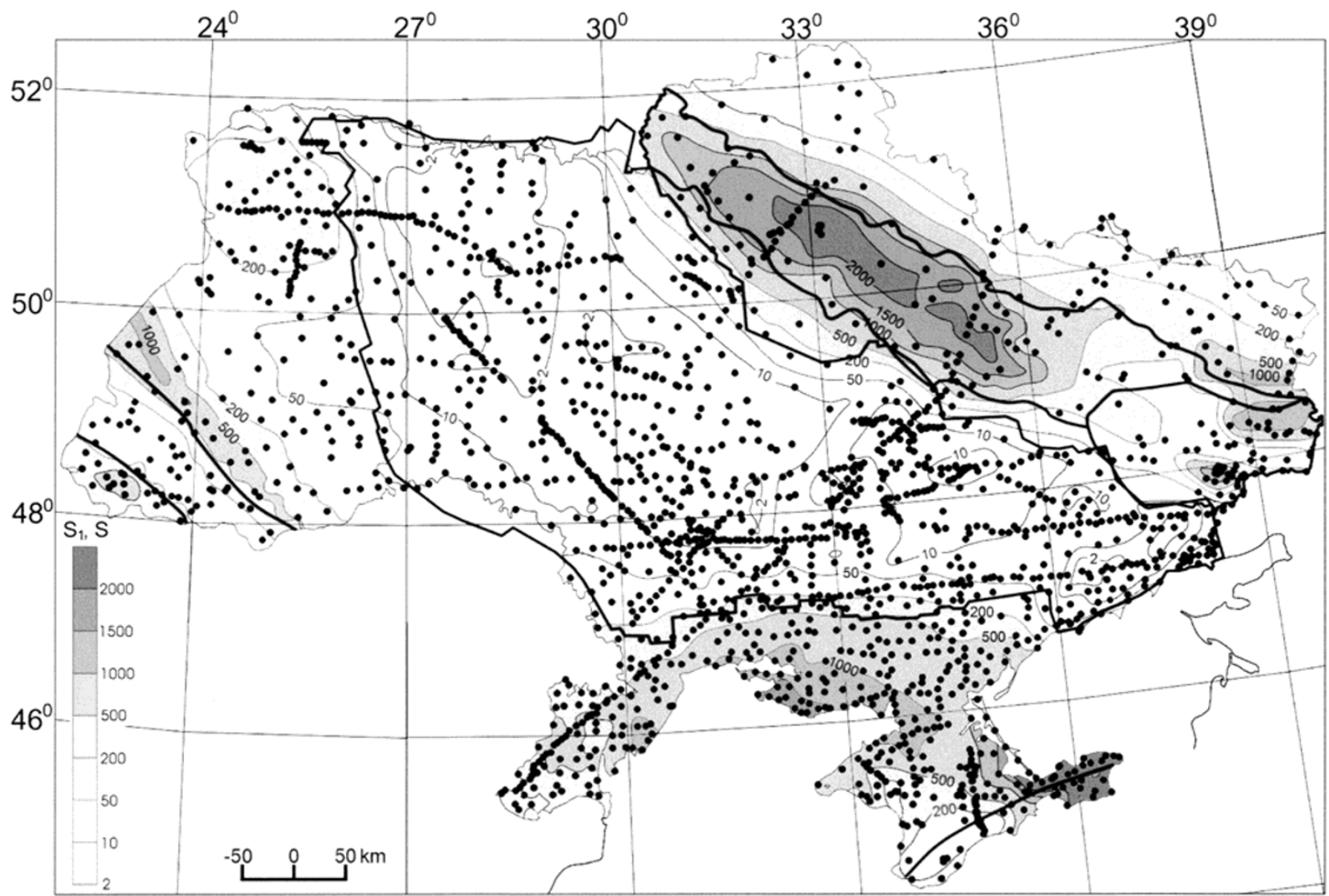

Fig. 2. Deep MTS observations (dots) and longitudinal conductivity S1 of sediments (isolines in S).

1982), Kirovograd (Rokityansky et al., 1976) and Donbas (Rokityansky et al., 1988, 1989, 1994). The first one is in the Alpine folded system of the Carpathians, the second in the Proterozoic basement of the Ukrainian shield, the third in the Carboniferous metamorphized sediments of the folded Donbas. Reliable geoelectromagnetic data for the three anomalies can be summarized as follows. Profile graphs of the horizontal and vertical anomalous fields for the Carpathian and Kirovograd anomalies are rather simple, suggesting a deep origin, and MTS data confirm the supposition: the upper edge of the conductor is approximately $10 \mathrm{~km}$ deep (see MTS curves C, K1-K4 in Fig. 3) for both anomalies. The moments of anomaly field (Rokityansky, 1982), the dependence on period (frequency response) are essentially the same yielding the same total longitudinal conductivity for the anomalous conductor: (2-3) $10^{8} \mathrm{Sm}$ in 2D approximation (Rokityansky, 1982). The Donbas anomaly exibits rather different bahaviour: sharp gradients of the anomalous field, apparent lack of correspondence between horizontal and vertical anomalous fields judged from the Hilbert transform (the possible cause may be a $30 \mathrm{~km}$ gap of data resulting from too strong industrial noise). Donbas' anomalous fields are a factor 2-3 larger than the Carpathian and Kirovograd ones, and the maximum of the frequency response is shifted to long periods $\left(T_{\max }=4000 \mathrm{~s}\right)$, which gives an estimate of the total longitudinal conductivity exceeding $10^{9} \mathrm{Sm}$. The depth of the conductor is $1-4 \mathrm{~km}$ according to MTS data (Fig. 3, D). The anomaly coincides with definite strata of Lower Carboniferous age and the only possible good con- ductor in the strata is a deeply metamorphos anthracite. The Donbas electrical conductivity anomaly is a very attractive place for EM studies: well-studied stratification checked by hundreds of mines and boreholes gives a unique possibility for natural modelling in a rather complicated geoelectrical environment when the results of the study can give rise to new coal output development.

\section{Integrated Conductivity of Sedimentary Cover S1}

Compilation of the data to set up a map of integrated longitudinal conductivity of sedimentary cover was begun years ago, and several regional maps have been constructed (Kondrashova, 1981; Kravchenko and Sapuzhak, 1980 and some unpublished work) The first difficult place for the map construction is the Ukrainian Shield. Some potential sites for deposits are covered by very dense observations and a lot of work has been done to find, analyse and interpolate the huge amount of dispersed data. Some places are studied very poorly; there extrapolation had been done incorporating all available geological and indirect geophysical data. The direct geoelectrical data used compoise dozens of thousands of VES, FDEM, TEM, MT soundings accomplished by geophysical prospecting and geological engineering parties during the last fifty years.

The second difficult places are the deep depressions and sedimentary basins. There, only MTS data contain information about the integral conductivity of the sediments, but the data are distorted both by inhomogenities in sediments 


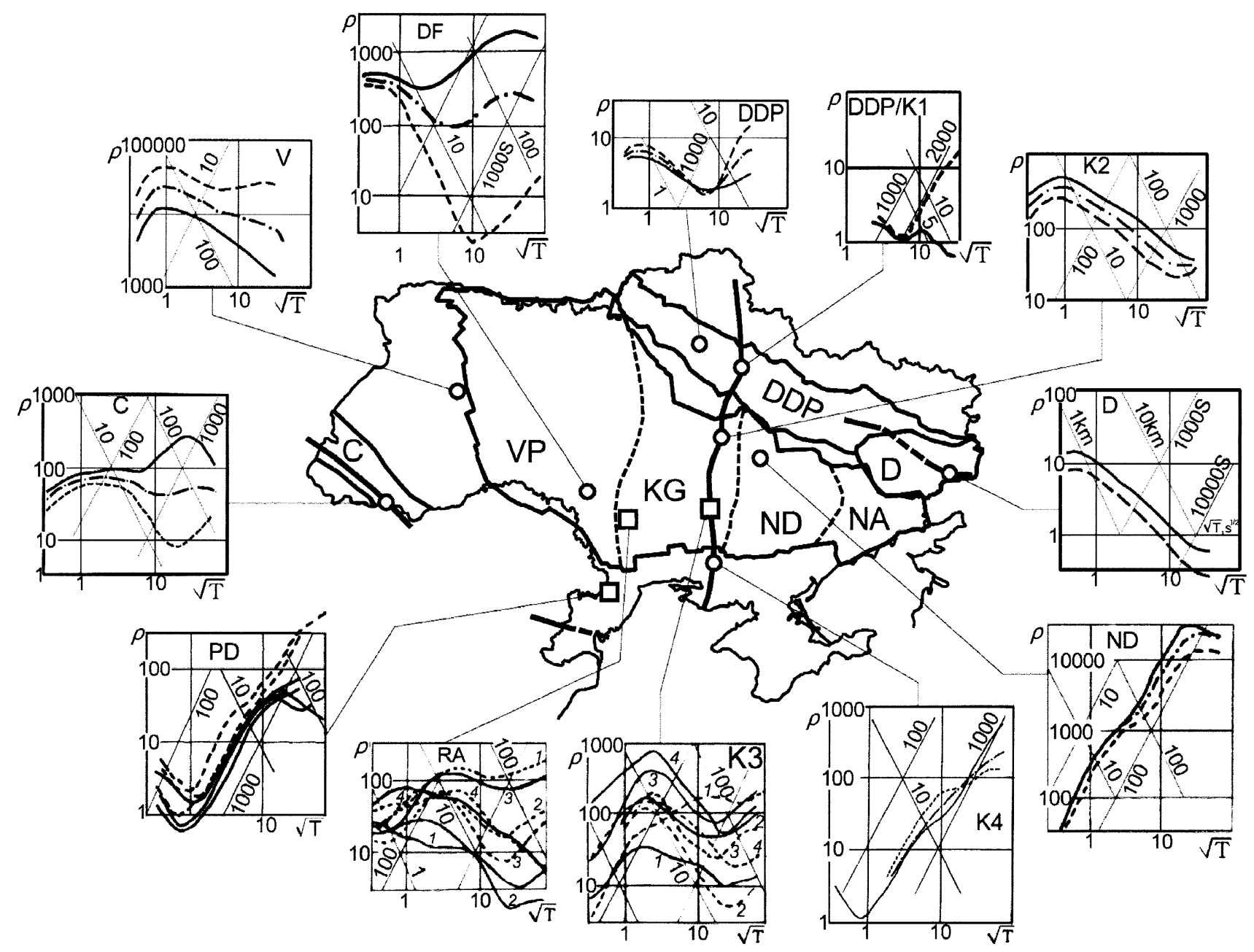

Fig. 3. Selected MTS curves. Solid lines are meridional (transverse in C, DDP and D units), dashed ones are longitudinal curves. Dashed with dots are effective ones.

and basement and by irregularities of the basement's relief. The third difficult places are the Crimean and Carpathian mountains because of topographic effects and complicated geology.

The S1 maps for the whole Ukraine are constructed at two scales: 1:1000000 and 1:2500000. Unfortunately, the first one is not ensured by adequate data in few regions. The 1:2500000 map can be considered as meeting the standard requirements. Evaluation of the final uncertainty of the map suggests $5-10 \%$ in favourable regions: slopes of the shield, flat Grimea, Pre-Carpathian and Pre-Dobrugian depressions (for some of the regions the $\mathrm{S} 1$ maps meeting the standard are built at the scale 1:500000, 1:200000 and 1:50000) and $10-30 \%$ in unfavourable $\langle$ difficult places $\rangle$ and maybe up to $40-50 \%$ in very unfavourable places. A scaled down, smoothed and thinned-out version of the S1 1:2500000 map is presented in Fig. 2. The map has been used for construction of thin sheet grid models.

\section{Thin Sheet Modelling}

The modelling was performed in 1989 with a rather rough net model containing $40 \times 30$ cells, $50 \times 50 \mathrm{~km}$ each. Calculations were performed by N. S. Golubtsowa at Moscow State University using the program of A. S. Debabov for 7 models differing only in their normal cross-sections. MTS
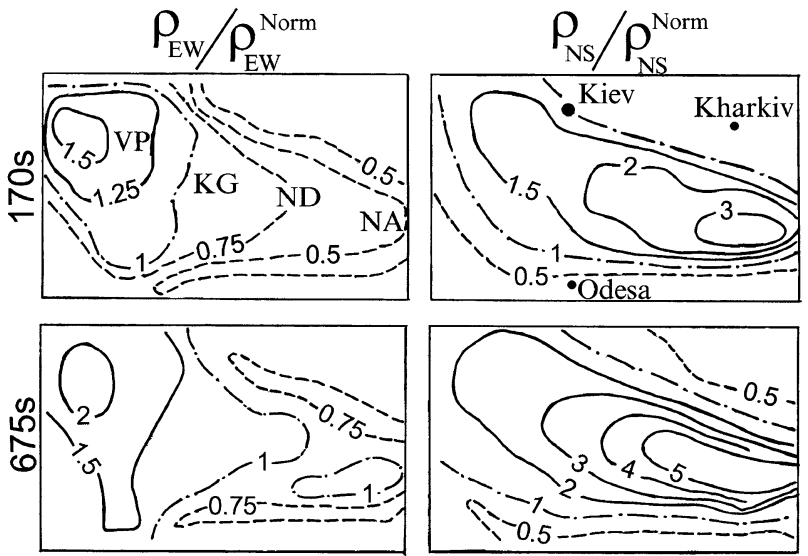

Fig. 4. Distortions (ratio of apparent resistivity for the thin film model to locally normal one) for two polarisations at two periods.

curves were built for every cell; their comparison with the observed natural MTS data reveals strong regional (then independent of the roughness of the models) discrepancies. No model with a 1D normal cross-section fits the natural data. An illustration of the modelling results is presented in Fig. 4 where maps of the distortions at two periods are given. 


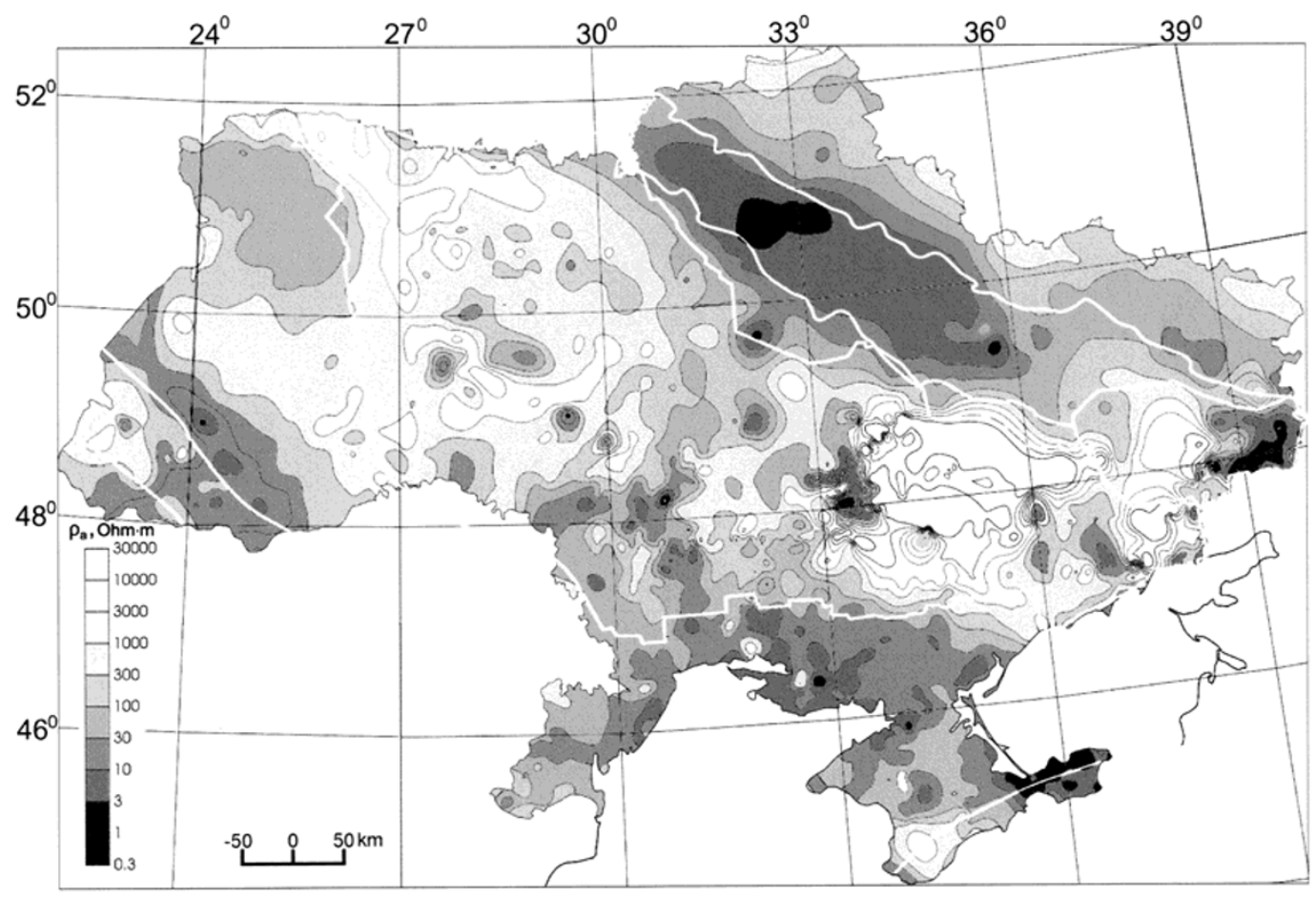

Fig. 5. Effective apparent resistivity at $T=150 \mathrm{~s}$.

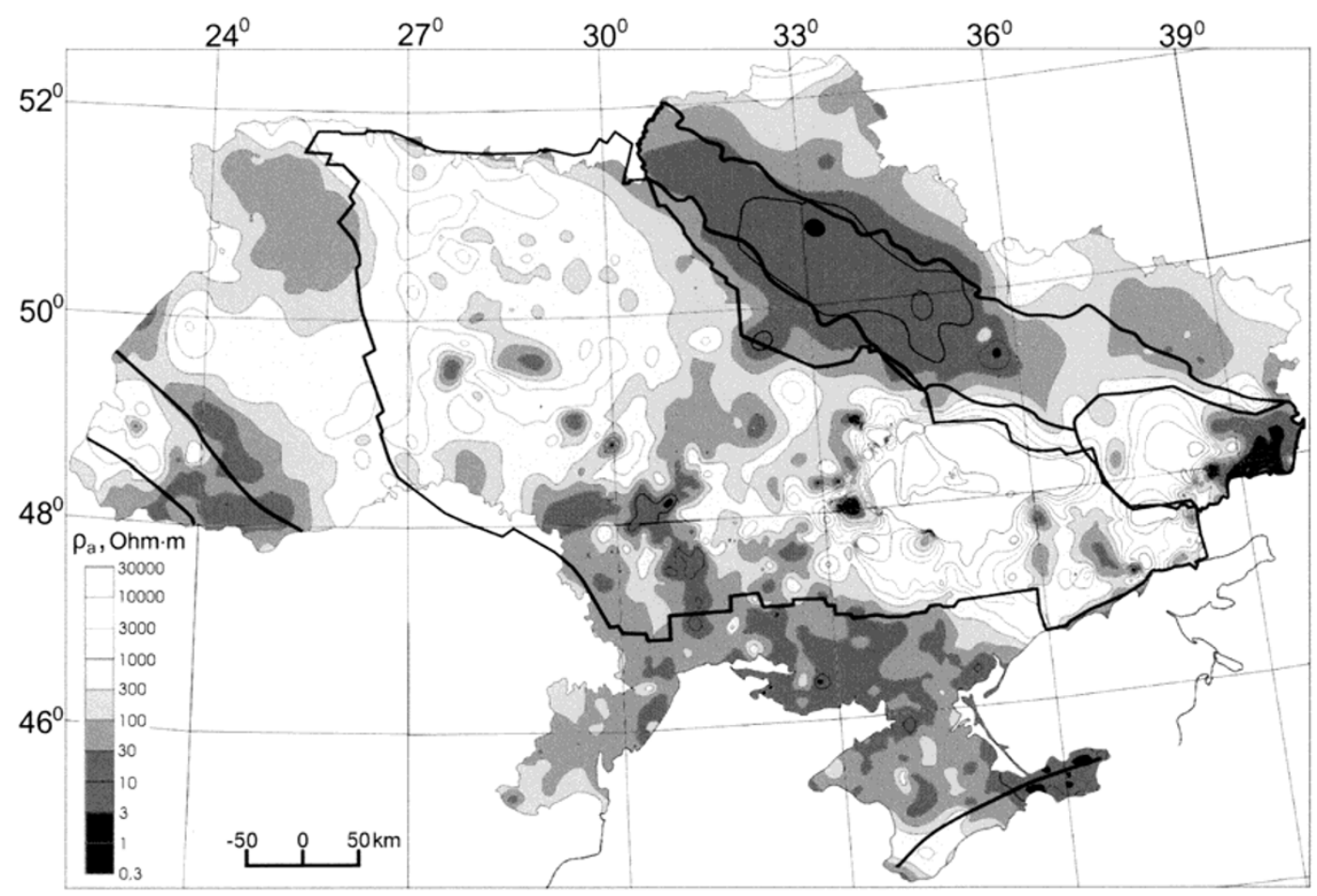

Fig. 6. Effective apparent resistivity at $T=500 \mathrm{~s}$. 


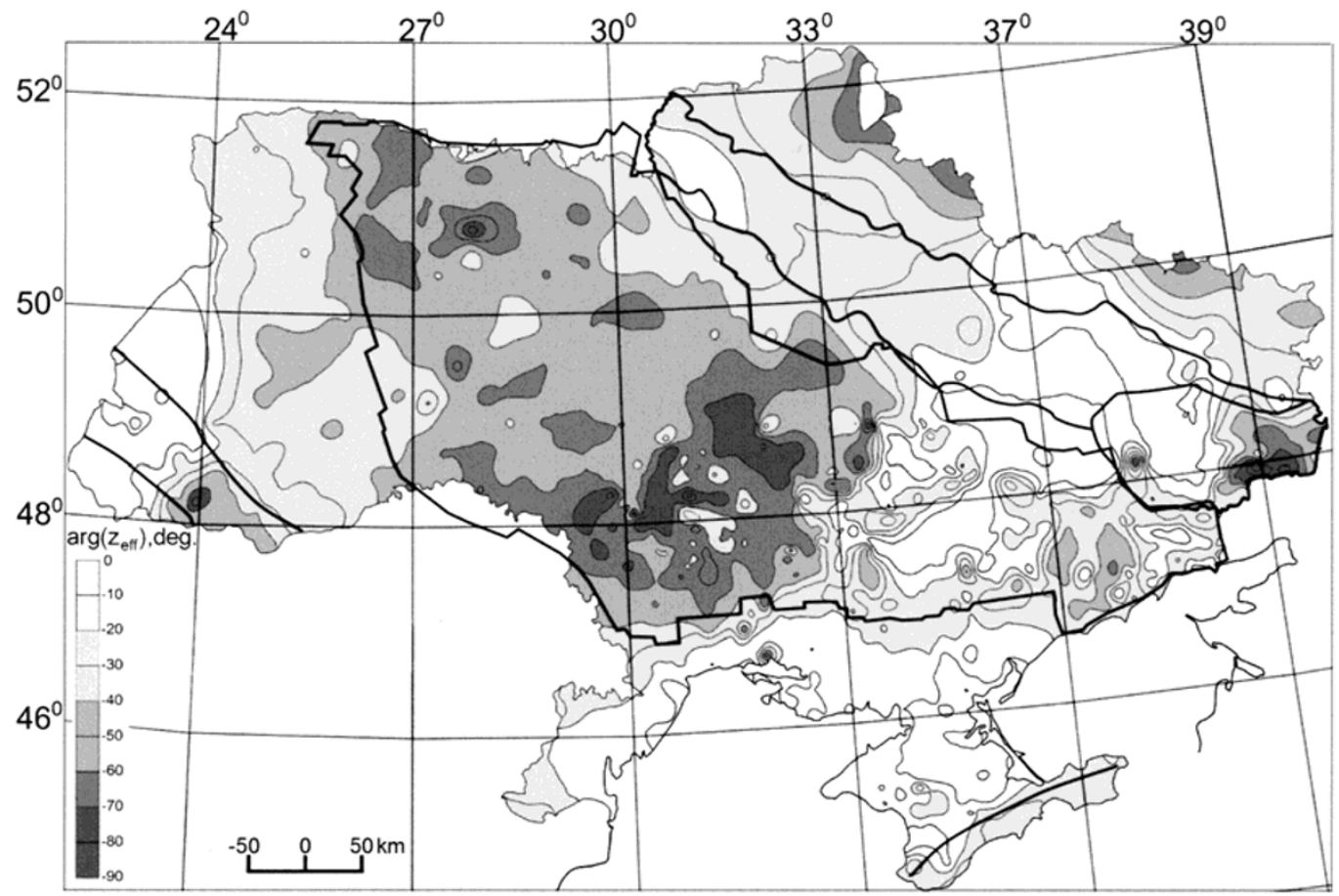

Fig. 7. Phase of effective impedance $\left(\arg Z_{e f f}\right)$ at $T=150 \mathrm{~s}$.

Dispersion of the distortions from regional S1 distribution is observed up to 2000-3000 s, and only for longer periods the distortions became static ones. According to the maps in the eastern half of the Ukrainian Shield, the Northern curve must be above the Eastern one by factor 5-10 in long periods. Observed natural curves do not exibit regional divergence. Hence, there is a regional system of crustal conductors including deep faults which strongly influence the MT field behaviour.

\section{Regional Maps of MTS Parameters}

A clear visualisation of a data can be given by a map of a response function at some period. As soon as the surface conductivity S1 is studied and known, our next goal is the study of crustal and mantle conductivity. For the goal, response functions at long periods are the most informative but the uncertainty of the response functions determination rises at long periods. We considered a set of maps constructed and made the choice to present first of all effective apparent resistivity at $150 \mathrm{~s}$ and $500 \mathrm{~s}$ and the phase of effective impedance $Z_{e f f}=\left(Z_{x x} Z_{y y}-Z_{x y} Z_{y x}\right)^{1 / 2}$ at $150 \mathrm{~s}$ (Figs. 57). These maps should be analyzed together with the S1 map in Fig. 2. Crustal conductors are clearly seen in the Ukrainian Shield but essentially screened by conductive sediments in depressions. Low values of apparent resistivity can manifest both crustal conductivity and sedimentary one. The phase at $150 \mathrm{~s}$, in contrast, can distinguish the two objects: sediments are characterized by a low value of the phase, deep crustal conductors by a high (absolute) value exeeding 45 degree and reaching 60-80 degree over the best conductors.

\section{Map of the Crustal Conductivity (Results and Problems)}

A principal result of our study is the following: we cannot show a place in the Ukraine where crustal conductor is definitely absent. The lowerst conductivity of the crust is seen in the Near-Dnieper block where slight inflection of ascending MTS curves can be interpreted as the manifestation of a conductor of total conductivity as small as several Siemens (Fig. 3, ND). However, MTS records in the ND block are very noisy, and observations should be repeated with the remote reference technique to check our data. Strong geoelectrical distortions are also expected there.

Working on the conducting sediments of longitudion conductivity $\mathrm{S} 1$ we can register a crustal conductor with total conductivity typically more than $(0.2-0.5) \mathrm{S} 1$ (the exact value depends on geological noise, distortions and accuracy of observation and processing). For example, the Kirovograd conductivity anomaly is clearly seen under $2000 \mathrm{~S}$ sediments of the Dnieper-Donetsk Paleorift (Fig. 3, DDP/K1), however it is practically not seen under $300-1200 \mathrm{~S}$ of the southern slope of the Ukrainian Shield (Fig. 3, K4) where it is reliably shown by MVP data (Fig. 1). Furthermore, disagreement of MVP and MTS results concerning the crustal conductor is observed in some regions over Carpathian and Donbas anomalies. In the SE part of Ukrainian Carpathians and in the Eastern part of the Ukrainian Donbas, MTS clearly show crustal conductors and determine their depth. In the Western direction, the crustal conductor abruptly disappears according to MTS data for both anomalies (see Figs. 5-7) but we know according to highly reliable MVP data (see Fig. 1), that conductivity anomalies run there in the WNW direction. Apart from the three conductivity anomalies discovered by the MVP technique we have no direct independent geoelectrical data for checking the MTS results. As resume we can suppose: If the MTS array data show a deep conductor, we can believe them; if the data do not manifest it our conclusions should be rather careful. 


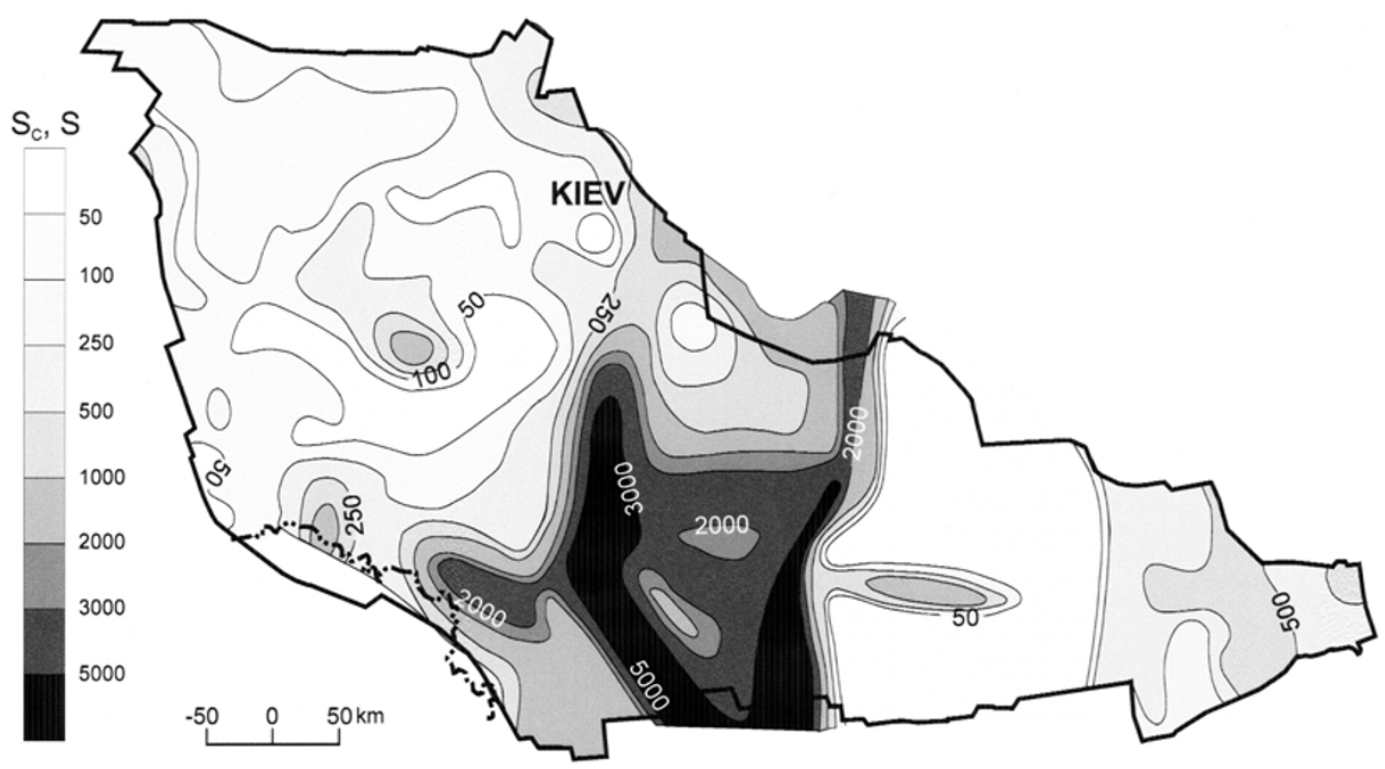

Fig. 8. Total longitudial conductivity of the crustal conductor in $\mathrm{S}$ for the Ukrainian Shield.

Taking into account the considerations mentioned we can study the map of crustal conductivity (Fig. 8). The map is based on 1D interpretation of MTS data and should be treated as preliminary. Nevertheless, the following interesting and reliable geological results are clearly seen: the younger the pre cambrian basement is, the more conductive are the crustal conductors (as they seen by MT soundings). The most conductive crustal conductors are situated in the Ryasnopol (3000-15000 S) and Indolo-Inguletz (10005000 S) Proterozoic structures (see MTS curves in Fig. 3, blocks RA and K1-K4). The Indolo-Inguletz crustal conductor manifests itself as the Kirovograd MVP conductivity anomaly. However, more conductive, according to MTS data, the Ryasnopol crustal conductor does not induce a pronounced anomaly in geomagnetic variations. It should be interpreted as a lack of the long distance electrical contact of the separate conductors composing the Ryasnopol anomaly and its longitudinal conductivity can be overestimated (3Deffect).

\section{Conclusion}

Extensive MT studies have been made in Ukraine and set of reliable results have been received which prove the effectiveness of MTS. Part of the data is waiting a mathematical and then geological interpretation to obtain more detailed and reliable results. In some regions new remote reference observations are required. In 1995 in the Ukraine new modern 6component multichannel digital MT stations with GPS synchronization for period band 0.05-100000 s have been constructed (Korepanov, Tregubenko), which was successfully used during the international MT campaign SVECALAPKO (1998).

\section{References}

Bondarenko, A. P., A. I. Bilinsky, and F. I. Sedova, Geoelectromagnetic Variations in the Soviet Carpathians, Kiev, 116 pp., Naukova Dumka, 1972.
Kondrashova, N. V., Longitudinal conductivity of sedimentary cover and water of Black and Azov sea aquatories, in Study of Earth Crust and Upper Mantle on Aquatories by Electromagnetic Methods, pp. 138-146, Moscow, IZMIRAN, 1981.

Kravchenko, A. P. and Y. C. Sapuzhak, Conductivity of sedimentary cover in the Carpathian region, Geophys. J., 2(N3), 73-78, 1980.

Rokityansky, I. I., On application of magnetotelluric method on anisotropic and inhomogenious massifs, Izv. Akad. Nauk SSSR, ser. Geophys., 11, 1607-1613, 1961.

Rokityansky, I. I., Coast effect in variations of the electromagnetic field of the Earth, Izv. Akad. Nauk SSSR, ser. Geophys., 12, 1814-1822, 1963.

Rokityansky, I. I., Investigation of the deep electrical conductivity, Geophys. Comm. Kiev, 38, 102-106, 1970.

Rokityansky, I. I., Deep magnetotelluric sounding at the presence of distortions from horizontal inhomogeneities, Geophys. Comm. Kiev, 43, 71-77, 1971.

Rokityansky, I. I., Anomaly of electrical conductivity in the Earth crust in Carpathians, Izv. Akad. Nauk SSSR, Fizika Zemly, N10, 97-100, 1972.

Rokityansky, I. I., Geoelectromagnetic Investigation of the Earth's Crust and Mantle, 381 pp., pp. 201-209, Berlin Heidelberg New York, Springer Verlag, 1982.

Rokityansky, I. I. and A. I. Ingerov, Geoelectrical studies in Ukraine, in Electromagnetic Soundings in the East-European Platform and Ural, Kiev, edited by A. G. Dyakonova, A. I. Ingerov, I. I. Rokityansky, pp. 353, Naukova Dumka, 1986.

Rokityansky, I. I., E. S. Lysenko, and D. A. Rokityanskaya, Anomaly of geomagnetic variations in Donbas, Doklady Akad. Nauk Ukrainy, Ser. B, N7, 12-15, 1988 .

Rokityansky, I. I., A. I. Ingerov, M. N. Baysarovich, K. I. Dzuba, A. A. Zhamaletdinov, E. S. Lysenko, V. M. Popov, D. A. Rokityanskaya, and V. N. Shuman, Donbas electrical conductivity anomaly, Geophys. J., 11(N3), 30-40, 1989.

Rokityansky, I. I., A. I. Ingerov, and E. S. Lysenko, New data on Donbas conductivity anomaly, Geophys. J., 16(N1), 67-72, 1994.

Rokityansky, I. I., S. N. Kulik, I. M. Logvinov, and V. N. Shuman, Deep magnetovariational studies in Ukraine, in Geoelectric and Geothermal Studies, KAPG Geoph. Mon., edited by A. Adam, pp. 634-639, Budapest, Akademiai Kiado, 1976.

Tikhonov, A. N., N. V. Lipskaya, and B. M. Yanovsky, Same results of the deep magnetotelluric investigation in the USSR, J. Geomag. Geoelectr., 15(N4), 275-279, 1964.

A. I. Ingerov (e-mail: alingers@aracnet.net), I. I. Rokityansky (e-mail: earth@igph.kiev.ua), and V.I. Tregubenko(e-mail: direct@kgou.ru.kiev.ua) 